\title{
Effect of plasma oxidation parameters on physical properties of nanocrystalline nickel oxide thin films grown by two-step method: DC sputtering and plasma oxidation
}

\author{
F. Hajakbari ${ }^{1}$ - S. Rashvand ${ }^{1}$ A. Hojabri ${ }^{1}$ \\ Received: 30 May 2019 / Accepted: 10 September 2019 / Published online: 19 September 2019 \\ (c) The Author(s) 2019
}

\begin{abstract}
Nanocrystalline nickel oxide (NiO) thin films were successfully grown on quartz substrates by two-step method. In the first step, nickel films were deposited on quartz substrates by DC magnetron sputtering technique. Then, the plasma oxidation of nickel films was used for preparation of nickel oxide. The effect of DC plasma power and treatment time on the structural, morphological and optical properties of the $\mathrm{NiO}$ films were investigated by different analyses. XRD results indicated that the plasma powers effectively influenced the structure of films, and the best crystallinity was obtained for plasma power of $15 \mathrm{w}$ and treatment time of $20 \mathrm{~min}$. The XPS, RBS and EDS analysis confirmed the presence of Ni and O elements. The FESEM and AFM images showed a granular structure with spherical shapes of grains. The optical band gap of the films synthesized under different plasma oxidation conditions was also discussed.
\end{abstract}

Keywords $\mathrm{NiO} \cdot$ Plasma treatment $\cdot$ Thin film $\cdot$ DC sputtering $\cdot$ Plasma power $\cdot$ Plasma time $\cdot$ Nanocrystalline

\section{Introduction}

In recent years, the preparation and characterization of nanostructure nickel oxide $(\mathrm{NiO})$ have gained considerable attentions of many scientists, due to excellent properties [1-20]. The properties of $\mathrm{NiO}$ thin films, which make it suitable for the different applications, are excellent durability, low material cost and wide optical band gap in the range of $3.6-4 \mathrm{eV}$, excellent electrical and optical properties [1-26]. Some applications of $\mathrm{NiO}$ thin films include gas sensors [1-5], positive electrode in Li-ion batteries [9], electrochromic display devices [12] and metal-isolator-metal tunnel junction diode [11]. NiO films can be fabricated by different physical and chemical deposition techniques such as DC and RF magnetron sputtering [2, 6, 11-15], thermal oxidation [16-18], chemical deposition $[19,20]$, pulsed laser deposition [9], spray pyrolysis [21] and sol-gel [23]. An alternative method for preparation of $\mathrm{NiO}$ films that recently was reported by our research group is plasma oxidation of nickel thin films

F. Hajakbari

fatemeh.hajakbari@kiau.ac.ir

1 Department of Physics, Karaj Branch, Islamic Azad University, Karaj, Iran
[7]. The oxidation process of thin metal films using plasma discharge offers many advantages compared with conventional process such as gas oxiding. In this technique, only the substrate holder and the workpiece are heated, which leads to significantly reduce the treatment times and energy cost and plays a large role in the success of low-temperature processes. Furthermore, the structure and morphology of thin films depend on many factors such as deposition techniques and parameters, composition of films, post-deposition processing and heat treatment [25-30]. Owing to advantages of plasma oxidation, an attempt was made on the fabrication of $\mathrm{NiO}$ films at different plasma oxidation conditions in this study. The focus of the present work is to investigate the effect of plasma treatment time and power on structural, morphological and optical properties of $\mathrm{NiO}$ films.

\section{Experimental details}

Nickel oxide $(\mathrm{NiO})$ thin films were prepared on quartz substrates by two-step method. In the first step, thin films of nickel (Ni) with $100 \mathrm{~nm}$ thicknesses were deposited on quartz substrates by direct current (DC) magnetron sputtering using a pure Ni target (99/999\%) and argon (Ar) gas. Prior to films deposition, the $1 \mathrm{~cm} \times 1 \mathrm{~cm}$ quartz substrates 
were cleaned ultrasonically in acetone and ethanol for $15 \mathrm{~min}$. Then, these substrates were placed at approximately $4 \mathrm{~cm}$ from the target into a sputtering chamber. The deposition chamber was evacuated to a base pressure $3 \times 10^{-5}$ mbar using the diffusion and rotary pumps combination. Then, $\operatorname{Ar}$ (99/999\%) gas was introduced into the deposition chamber and the working pressure was kept $8 \times 10^{-3}$ mbar. Before deposition, the target was pre-sputtered for $10 \mathrm{~min}$ in pure Ar. The deposition of Ni films was done at room temperature for deposition time of $60 \mathrm{~min}$.

In this work, we want to prepare $\mathrm{NiO}$ films at low plasma powers; therefore, in the second step, in order to synthesize nickel oxide films, the $\mathrm{Ni}$ thin films were treated with oxygen plasma for different DC powers of 9 , 15, $22 \mathrm{w}$ (samples: $\mathrm{Q}_{\mathrm{p} 1}, \mathrm{Q}_{\mathrm{p} 2}, \mathrm{Q}_{\mathrm{p} 3}$ ) and different times of 10, 20, 30 min (samples: $Q_{t 1}, Q_{t 2}, Q_{t 3}$ ) in plasma chamber of cylindrical magnetron sputtering system. The detail of the system can be found in ref. [31]. The crystal structure of films was identified by X-ray diffraction (XRD) analysis (XRD, Philips, pw 1800) with Co $(\lambda=0.17890 \mathrm{~nm})$ radiation. The film morphology was examined by atomic force microscopy (AFM, Park Scientific Instrument, Auto probe cp USA) and field emission scanning electron microscopy (FESEM, Hitachi S-4160) which was equipped with an energy dispersive X-ray spectroscopy (EDS) system. The composition of films was evaluated by Rutherford backscattering spectroscopy (RBS) using a $2 \mathrm{MeV}$ proton beam of a 3 MV single ended Van de Graff machine [7, 28]. The surface chemistry and composition of some $\mathrm{NiO}$ films were investigated by X-ray photoelectron spectroscopy (XPS) with Al K $\alpha$ X-ray source $(h \nu=1486.6 \mathrm{eV})$. The optical transmittance spectra of the NiO films were measured over the range from 200 to $1100 \mathrm{~nm}$ with a (CARY 500 Scan) spectrophotometer.

\section{Results and discussion}

XRD pattern of the NiO films grown on quartz substrates at different plasma treatment powers and times are shown in Fig. 1a, b, respectively. Figure 1a shows the XRD pattern of the NiO films prepared at different plasma oxidation powers. In all cases, the treatment duration is equal to $20 \mathrm{~min}$. The XRD spectrum of the film prepared at power of $9 \mathrm{w}$ exhibits a diffraction peak corresponding to (111) crystal plane of NiO, according to JCPDS card No. 78-0643. By increasing the plasma power to $15 \mathrm{w}$, the (111) peak intensity increases. According to XRD results, the NiO (111) was observed for two samples but for plasma power of 15 $\mathrm{w}$, the intensity of the (111) peak is very intensive compared to the samples prepared at $9 \mathrm{w}$. For plasma power of $22 \mathrm{w}$, the intensity of the (111) peak intensively decreased and a new peak appeared at $2 \theta=36.25^{\circ}$ is belong to (002) reflection plane of $\mathrm{Ni}_{2} \mathrm{O}_{3}$ (JCPDS card No. 00 - 014 - 0481) and similar to other samples that prepared at plasma power of 9 and $15 \mathrm{w}$, a weak peak of $\mathrm{NiO}$ (111) was observed at $2 \theta=42.48^{\circ}$. Moreover, the observed peaks at XRD spectra are sharp and high intense which confirms the well crystallization of the obtained $\mathrm{NiO}$ structures. These results clearly show that the plasma treatment power effectively influenced the structure of films. From the XRD results, we observed that the best crystallinity belongs to the sample prepared at plasma power of $15 \mathrm{w}$. Thus, the plasma power was fixed at $15 \mathrm{w}$ and we changed the treatment times from 10 to $30 \mathrm{~min}$.
Fig. 1 The XRD spectra of the $\mathrm{NiO}$ films grown on quartz substrates at different plasma treatments: a powers and $\mathbf{b}$ times
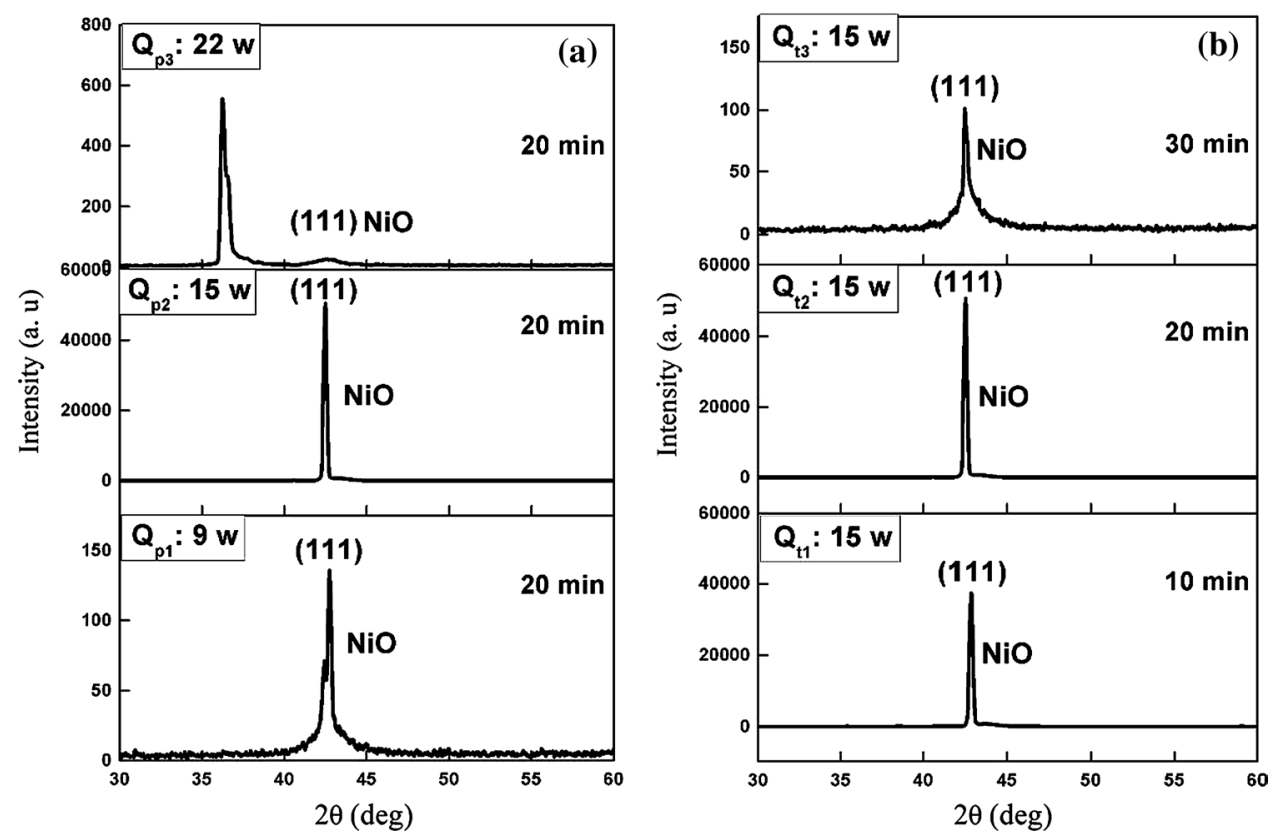
The treatment duration was 10, 20 and 30 min (Fig. 1b). The XRD patterns of these films reveal a diffraction peak corresponding to (111) reflection plane of $\mathrm{NiO}$. In addition, the XRD patterns exhibited by increasing of plasma oxidation time from 10 to $20 \mathrm{~min}$ the $\mathrm{NiO}$ (111) peak intensity increased, and further increase in time to $30 \mathrm{~min}$ leads to decrease in intensity of this peak. The high intense and narrow (111) peak observed in XRD patterns of films prepared at different plasma treatment times reveal that these films have better crystallinity, which can be attributed to fewer defect states in the films. The structural studies also revealed that the good crystallinity was observed for the oxygen plasma treatment power of $15 \mathrm{w}$ for treatment duration of $20 \mathrm{~min}$. Figure 1.b also shows that the position of $\mathrm{NiO}$ (111) peak shifted to lower angles as the plasma treatment times increases may be due to the increasing of the strain within the crystals. Based on the XRD results we can observe that plasma oxidation of nickel films to be able to generate a good quality nanocrystalline $\mathrm{NiO}$ films without any annealing or substrate temperatures, which is an advantage of this techniques compared to other published works. The average crystallite size $(D)$ of the $\mathrm{NiO}$ films was calculated for (111) peak by Debye-Scherrer's formula [23].

$D=0.9 \lambda / \beta \cos \theta$,

where $\lambda$ is the wavelength of the Cok $\alpha$ radiation $(\lambda=0.17890 \mathrm{~nm}), \beta$ is the full width at half maximum (FWHM) corresponding to diffraction angle $\theta$. The dislocation density $(\delta)$ defined as the length of dislocation lines per unit area of the crystal. The values of $(\delta)$ are estimated by Eq. 2 [28].

$\delta=1 / D^{2}$,

The strain $(\varepsilon)$ values for films are calculated with Eq. 3 [28].

$\varepsilon=\beta / 4 \tan \theta$,

The structural parameters values calculated from XRD profiles were given in Table 1. According to the data of
Table 1, the variation of dislocation density values with plasma treatment power and time is similar to the microstrain values. In addition, the best crystallinity was observed at plasma power of $15 \mathrm{w}$. Therefore, this power was kept constant and we changed the treatment times from 10 to 30 min for samples $Q_{t 1}, Q_{t 2}$ and $Q_{t 3}$. In these samples, the microstrain and dislocation density increased with increasing the plasma treatment time while the crystallite size decreased. On the other hand, the average crystallite size of the films calculated from XRD data is found in the range of $29-41 \mathrm{~nm}$, which confirms the presence of nanocrystals in the NiO films prepared in this study [7, 24, 28]. Based on these results, plasma oxidation can be suitable technique for producing the nanocrystalline $\mathrm{NiO}$ films.

An effective XPS analysis was employed to study the chemical composition of $\mathrm{NiO}$ films. Figure 2 provides a typical XPS spectrum of $\mathrm{NiO}$ thin film prepared at optimum plasma power and time $\left(\right.$ Sample $\left.\mathrm{Qt}_{2}\right)$. The peaks detected at binding energies of $855.8 \mathrm{eV}$ and $862.1 \mathrm{eV}$ are corresponding to $\mathrm{Ni} 2 p_{3 / 2}$ and $\mathrm{Ni} 2 p_{1 / 2}$, respectively. These peaks suggest the presence of $\mathrm{NiO}[3,7,9,16]$. The peak detected at 529.63 is belonging to $\mathrm{O} 1 \mathrm{~s}$ and originates from the oxygen bond of Ni-O-Ni [7]. Furthermore, the XPS spectrum of $\mathrm{NiO}$ film in $\mathrm{Ni} 2 p$ range shown in Fig. $2 \mathrm{~b}$ exhibits four separated peaks belong to $\mathrm{Ni} 2 p_{3 / 2}$ and $\mathrm{Ni} 2 p_{1 / 2}$. The two peaks observed at binding energies of 855.8 and $862.1 \mathrm{eV}$ confirmed the presence of $\mathrm{Ni}^{+2}$ and $\mathrm{Ni}^{3+}$ for lower and higher binding energies, respectively. The $\mathrm{Ni}^{3+}$ peak can be associated to the formation of a $\mathrm{Ni}_{2} \mathrm{O}_{3}$ phase or a structure containing $\mathrm{Ni}^{2+}$ ions with holes. It has to be noted that no peaks related to the $\mathrm{Ni}_{2} \mathrm{O}_{3}$ phase were detected in the XRD spectra suggesting that if present, $\mathrm{Ni}_{2} \mathrm{O}_{3}$ occurs in an amorphous form [3].

The two and three-dimensional (2D and 3D) AFM images, the plot of surface roughness variations and topographic height histogram of $\mathrm{NiO}$ films prepared at different oxygen plasma powers and times are presented in Figs. 3, 4, 5 and 6 . According to AFM images of Figs. 3a-c, a granular structure with spherical shapes of grains can be observed for all samples prepared at different oxygen plasma powers.

Table 1 Structural parameters values of nickel oxide thin films

\begin{tabular}{llllllllll}
\hline Sample name & $\begin{array}{l}\text { Plasma } \\
\text { power } \\
(\mathrm{w})\end{array}$ & $\begin{array}{l}\text { Plasma } \\
\text { time } \\
(\mathrm{min})\end{array}$ & Phase & $\begin{array}{l}\text { Miller } \\
\text { indices } \\
(\mathrm{hkl})\end{array}$ & $\begin{array}{l}\text { Diffraction } \\
\text { angle }(2 \theta)\end{array}$ & FWHM (rad) & $\begin{array}{l}\text { Average } \\
\text { crystallite size } \\
(\mathrm{nm})\end{array}$ & $\begin{array}{l}\text { Microstrain } \\
\varepsilon\left(\times 10^{-3}\right)\end{array}$ & $\begin{array}{l}\text { Dislocation density } \\
\delta\left(\times 10^{+15} \text { line/m }\right.\end{array}$ \\
\hline $\mathrm{Q}_{\mathrm{p} 1}$ & 9 & 20 & $\mathrm{NiO}$ & $(111)$ & 42.74 & 0.00488 & 36 & 3.13 & 0.77 \\
$\mathrm{Q}_{\mathrm{p} 2}$ & 15 & 20 & $\mathrm{NiO}$ & $(111)$ & 42.49 & 0.00431 & 39 & 2.76 & 0.66 \\
$\mathrm{Q}_{\mathrm{p} 3}$ & 22 & 20 & $\mathrm{Ni}_{2} \mathrm{O}_{3}$ & $(002)$ & 36.25 & 0.00576 & 29 & 4.36 & 1.19 \\
$\mathrm{Q}_{\mathrm{t} 1}$ & 15 & 10 & $\mathrm{NiO}$ & $(111)$ & 42.83 & 0.00418 & 41 & 2.67 & 0.59 \\
$\mathrm{Q}_{\mathrm{t} 2}$ & 15 & 20 & $\mathrm{NiO}$ & $(111)$ & 42.49 & 0.00431 & 39 & 2.76 & 0.66 \\
$\mathrm{Q}_{\mathrm{t} 3}$ & 15 & 30 & $\mathrm{NiO}$ & $(111)$ & 42.44 & 0.00523 & 33 & 3.35 & 0.92 \\
\hline
\end{tabular}


Fig. 2 a XPS spectra of the $\mathrm{NiO}$ thin film and $\mathbf{b}$ XPS spectrum in the Ni $2 p$ range
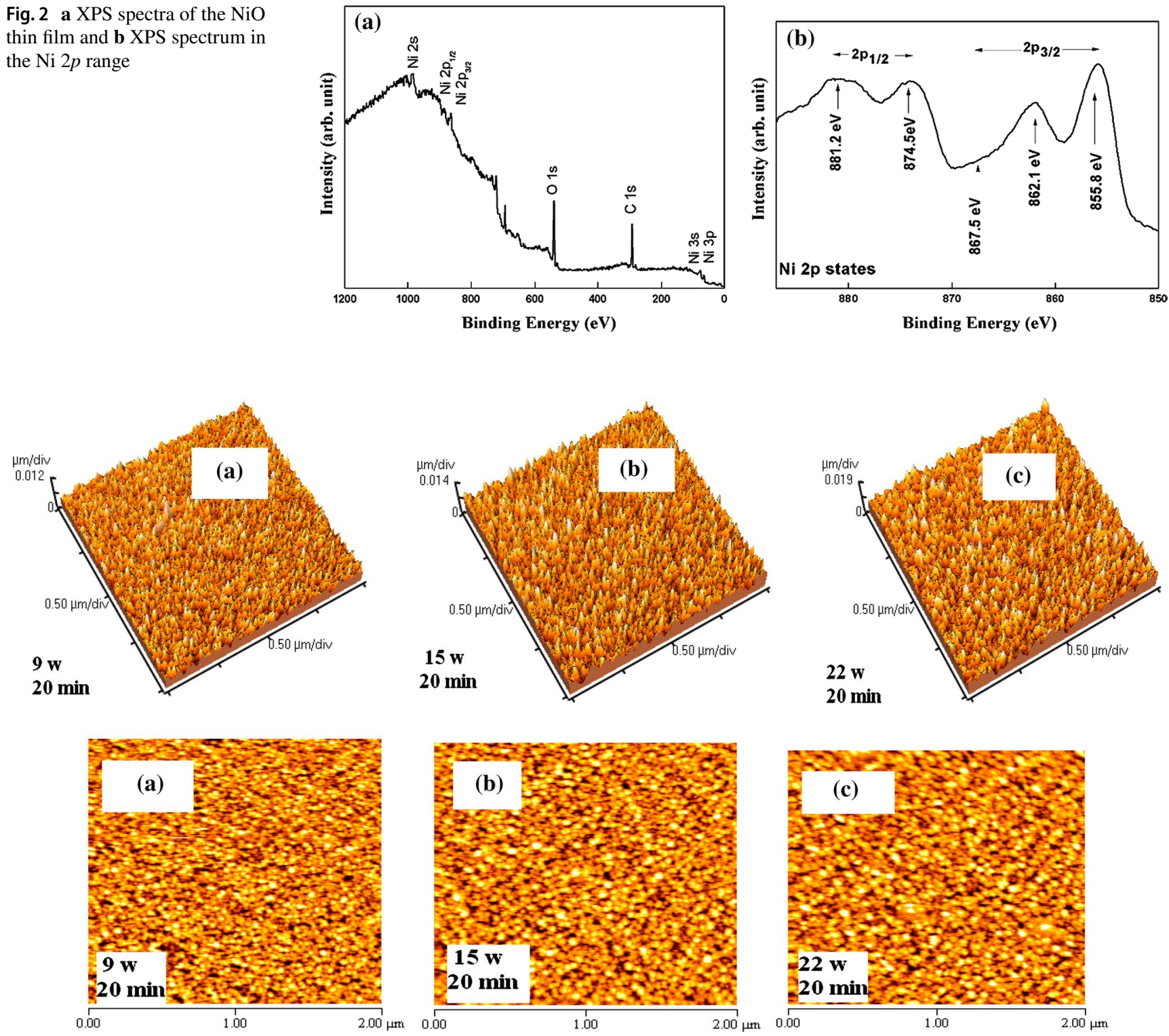

$20 \mathrm{~min}$

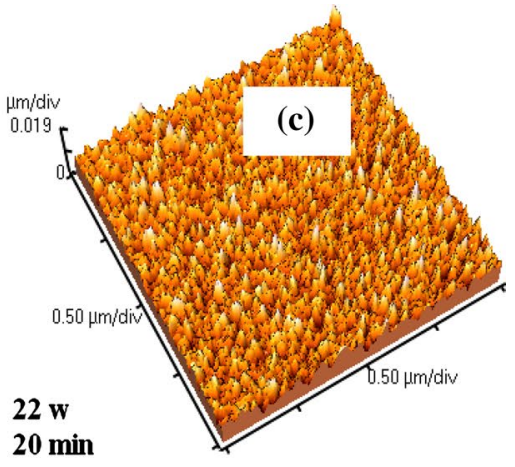

(c)

Fig. 3 The 3D and 2D AFM images of the $\mathrm{NiO}$ films grown on quartz substrate at different oxygen plasma powers: a $9 \mathrm{w}, \mathbf{b} 15 \mathrm{w}$ and $\mathbf{c} 22 \mathrm{w}$
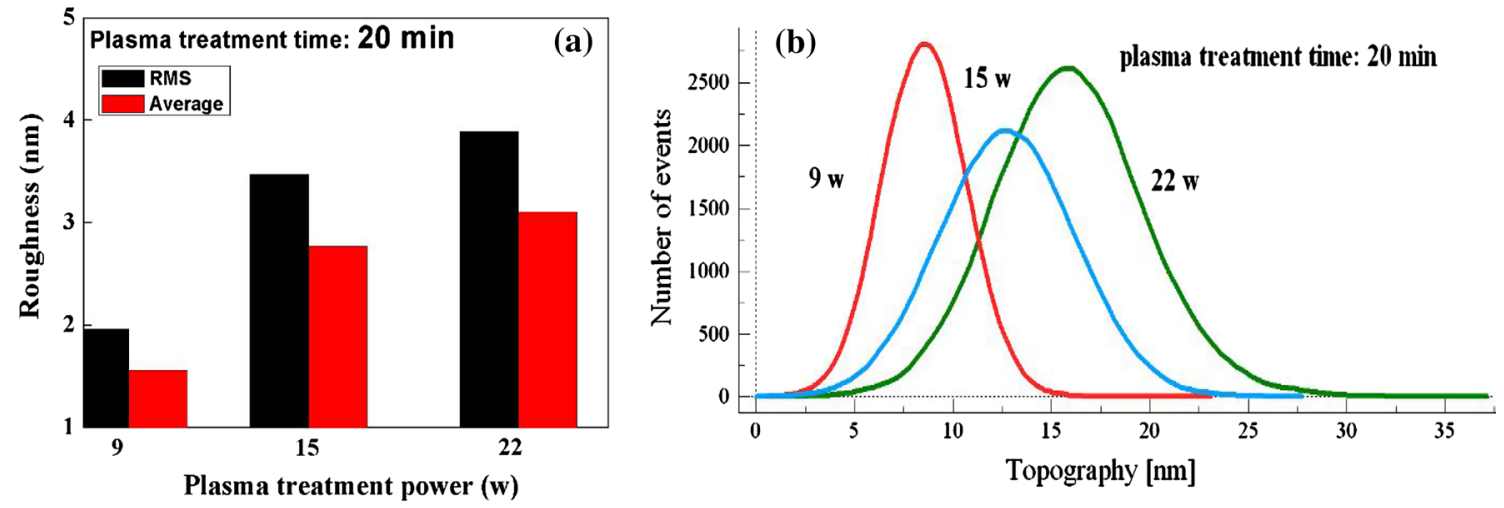

Fig. 4 a The plot of surface roughness of the $\mathrm{NiO}$ films versus oxygen plasma powers and $\mathbf{b}$ topographic histogram images 

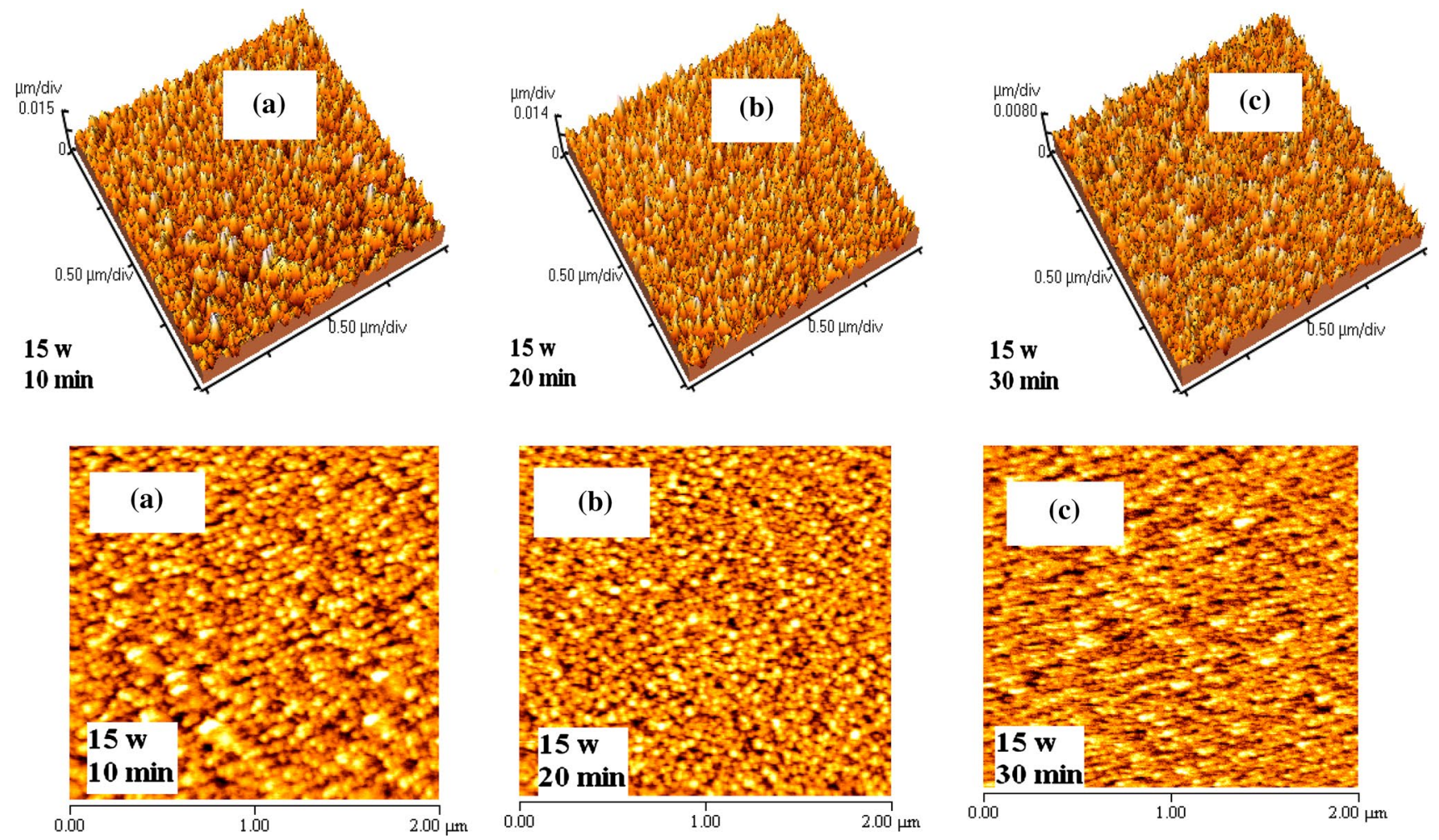

Fig. 5 The 3D and 2D AFM images of the NiO films grown on quartz substrate at different plasma treatment times: a 10 min, b 20 min and c $30 \mathrm{~min}$
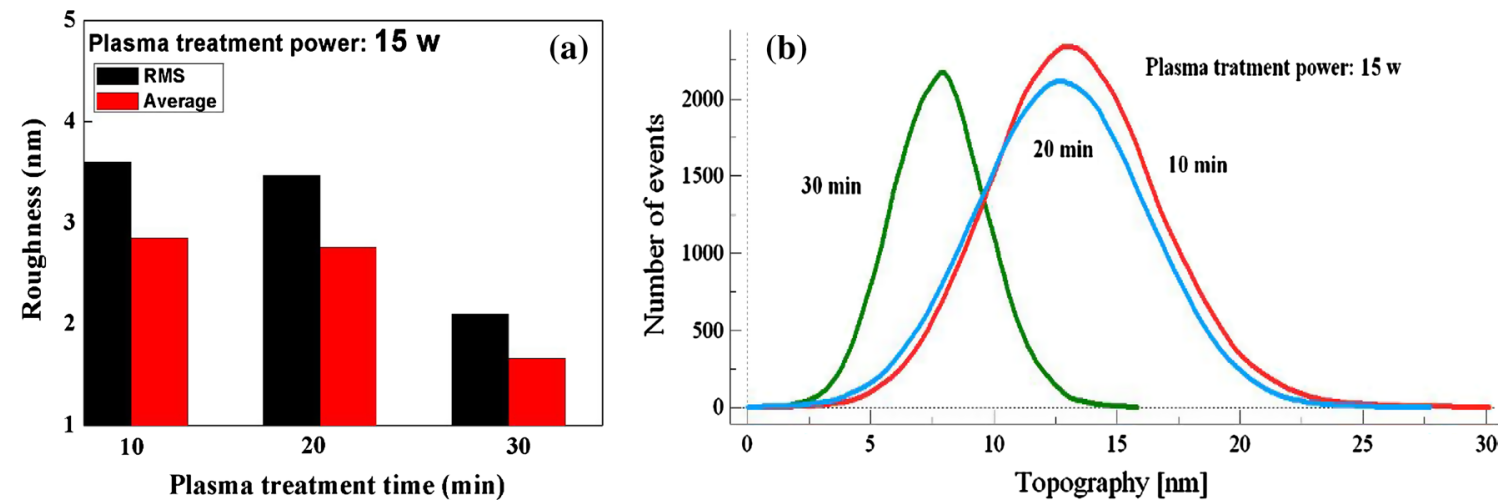

Fig. 6 a The plot of surface roughness of the $\mathrm{NiO}$ films versus plasma treatment times and $\mathbf{b}$ topographic histogram images

In addition, by increasing of plasma treatment powers, the grain size and the roughness of films increased. The plot of root-mean-square (RMS) roughness and average roughness versus plasma powers and topographic height histogram are shown in Figs. 4a, b. The histogram profiles of the surface height distribution show a shape of Gaussian distribution that confirmed the homogeneity of the films, and the surface roughness is increased by peak broadening in the height distribution profiles [7]. The roughness values are shown in Table 2.
Figures 5 and 6 present the AFM images, the plot of roughness and topographic height histogram of $\mathrm{NiO}$ films at different plasma treatment times. Similar to the films prepared at different plasma powers in these films, the granular structure with spherical shapes of grains is formed while the roughness of films decreased by augmentation of plasma times.

The surface morphology of the NiO films was also characterized using FESEM observations. Figure 7 displays the influence of the different plasma treatment times on the 
Table 2 The surface roughness values of nickel oxide thin films

\begin{tabular}{lllll}
\hline Sample name & $\begin{array}{l}\text { Plasma } \\
\text { power } \\
(\mathrm{w})\end{array}$ & $\begin{array}{l}\text { Plasma treat- } \\
\text { ment time } \\
(\mathrm{min})\end{array}$ & $\begin{array}{l}\text { RMS } \\
\text { roughness } \\
(\mathrm{nm})\end{array}$ & $\begin{array}{l}\text { Average } \\
\text { roughness } \\
(\mathrm{nm})\end{array}$ \\
\hline $\mathrm{Q}_{\mathrm{p} 1}$ & 9 & 20 & 1.96 & 1.56 \\
$\mathrm{Q}_{\mathrm{p} 2}$ & 15 & 20 & 3.47 & 2.77 \\
$\mathrm{Q}_{\mathrm{p} 3}$ & 22 & 20 & 3.89 & 3.10 \\
$\mathrm{Q}_{\mathrm{t} 1}$ & 15 & 10 & 3.60 & 2.85 \\
$\mathrm{Q}_{\mathrm{t} 2}$ & 15 & 20 & 3.47 & 2.76 \\
$\mathrm{Q}_{\mathrm{t} 3}$ & 15 & 30 & 2.10 & 1.66 \\
\hline
\end{tabular}

morphology and particle size of the $\mathrm{NiO}$ films grown on quartz substrates. According to FESEM images, the films have homogeneous and uniform surfaces since the films have no cracks and perfectly adhere to the substrates. The dense spherical-shaped grains and crack-free high compact surfaces imply a good crystallinity of films. According to SEM image of samples prepared at different plasma treatment times, the grain size decreases by increasing of plasma treatment time and has a similar trend to crystallite size calculated by XRD. The results of FESEM are consistent with XRD results that observed in Fig. 1b. In addition, the uniform nanosphere grains confirm the results obtained by AFM analysis.

The chemical composition of $\mathrm{NiO}$ films was quantified by an energy dispersive spectroscopy (EDS) method in FESEM measurements. The EDS spectrum in Fig. 8 clearly reveals the presence of only peaks corresponding to $\mathrm{Ni}$ and $\mathrm{O}$ elements within the limit of the EDS measurement. The appearance of Si peak is also attributed to the substrate. There are no peaks related to the elements other than $\mathrm{Ni}$ and $\mathrm{O}$ in the EDS spectra, which reveal the pure phase formation of $\mathrm{NiO}$ thin film and is consistent with XRD results.

To investigate the films composition, we employed the RBS technique. The RBS spectra of nickel oxide films

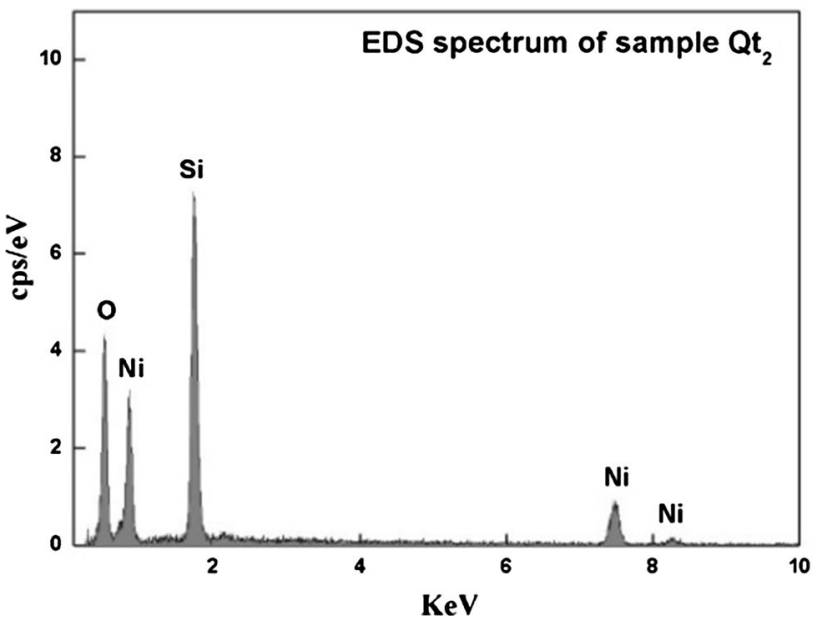

Fig. 8 Typical EDS spectrum of the NiO films grown on quartz substrates

prepared at different plasma oxidation powers and times are displayed in Fig. 9a, b, respectively. The different peaks are well separated, indicating that there is no interdiffusion at the interface between $\mathrm{Ni}$ and the substrates. The signals of the elements of the film such as $\mathrm{Ni}, \mathrm{O}$ as well as Si substrate are clearly observed in the spectra. The ion scattering from $\mathrm{Ni}$ atoms occurs at higher backscattering energy. This is because the backscattered energy of the incident ions is depending on the atomic mass of the elements from which the ions backscatters. The atomic masses of the elements are 15.99, 28.09 and 58.69 for $\mathrm{O}, \mathrm{Si}$ and $\mathrm{Ni}$, respectively, and the $\mathrm{Ni}$ is the heaviest among the elements either in the film or in the substrate.

Accurate information about the optical properties of $\mathrm{NiO}$ thin films is very important for technological applications. Therefore, in the following, we focus on the optical studies of the prepared $\mathrm{NiO}$ thin films. The optical transmittance spectra of the NiO thin films prepared at different plasma
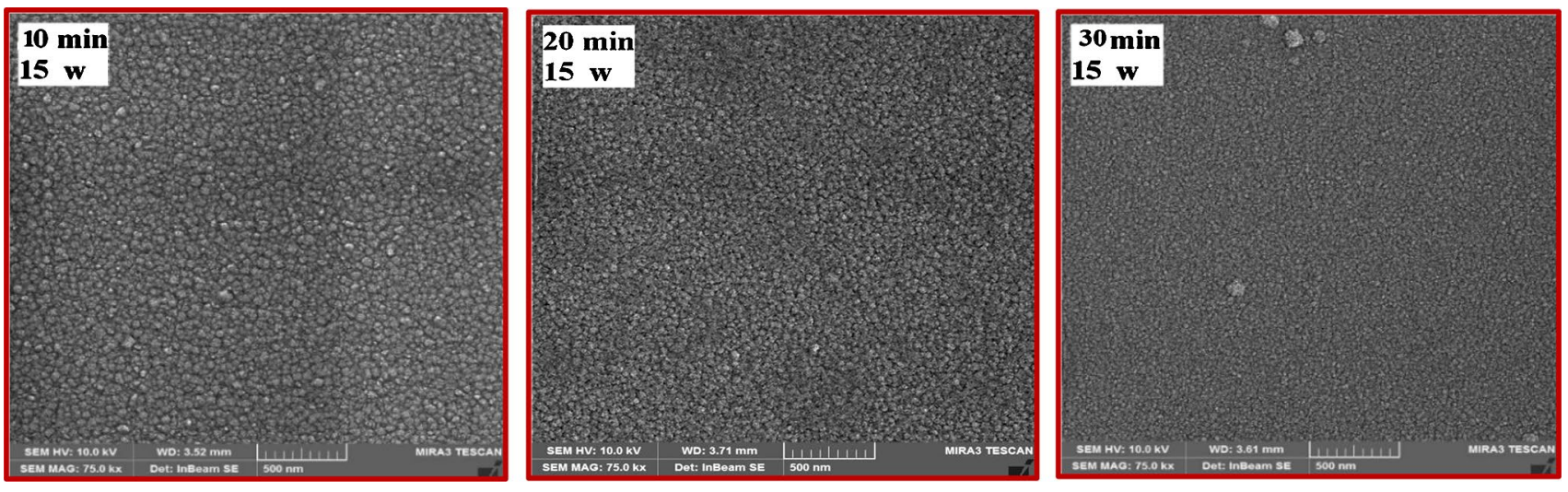

Fig. 7 FESEM micrographs of the $\mathrm{NiO}$ films prepared at different plasma treatment times 

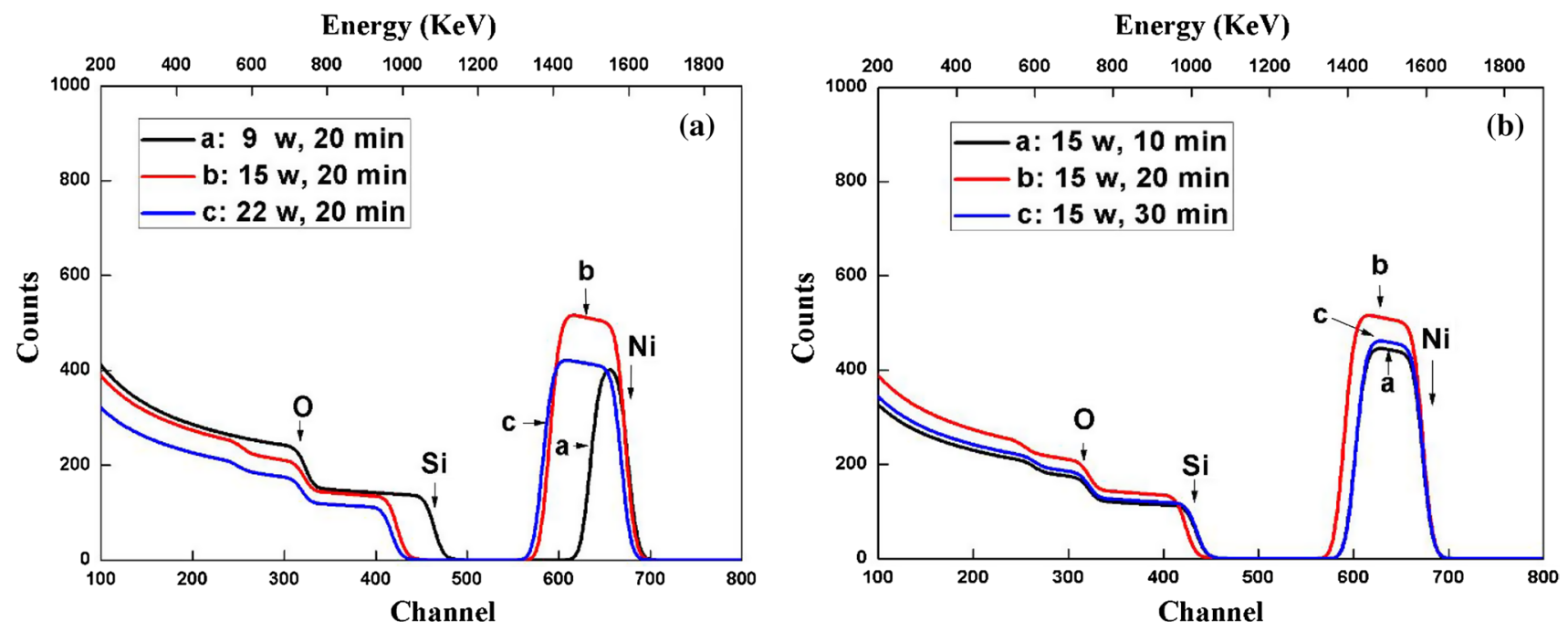

Fig. 9 The RBS spectra of the NiO films grown on quartz substrates at different plasma treatment: a powers and $\mathbf{b}$ times

treatment powers and times on quartz substrates as a function of wavelength in range of $200-1100 \mathrm{~nm}$ are shown in Fig. 10a, b, respectively. According to transmittance spectra of the prepared films at different plasma treatment times, the DC plasma power of $15 \mathrm{w}$ for $20 \mathrm{~min}$ has the lowest transmittance. According to XRD results, the best crystallinity was obtained for this film. Therefore, due to the increase in light scattering from this film the transmittance decreased. In addition, the optical transmittance of films increased by enhancing the plasma treatment time to 30 min may be due to the reduction of films crystallinity and surface roughness, which can be observed by XRD and AFM.

The optical absorption coefficient $(\alpha)$ can be estimated using the following formula. $\alpha=1 / d(\ln 1 / T)$

where $T$ is the optical transmittance, and $\mathrm{d}$ is the thickness of film. The optical band gap energy $\left(E_{\mathrm{g}}\right)$ of the films can be calculated from the dependence of absorption coefficient $(\alpha)$ on the incident photon energy $(h \nu)$ [28].

$\alpha h v=B\left(h v-E_{\mathrm{g}}\right)^{p}$

where $B$ is a constant that depends on the transition probability, and $\mathrm{p}$ is an exponent, which depends on the type of optical transition between the valence and conduction band direct or indirect. For the crystalline semiconductors, $\mathrm{p}$ is theoretically equal to $1 / 2,3 / 2,2$ or 3 for the direct allowed, direct forbidden, indirect allowed and indirect forbidden
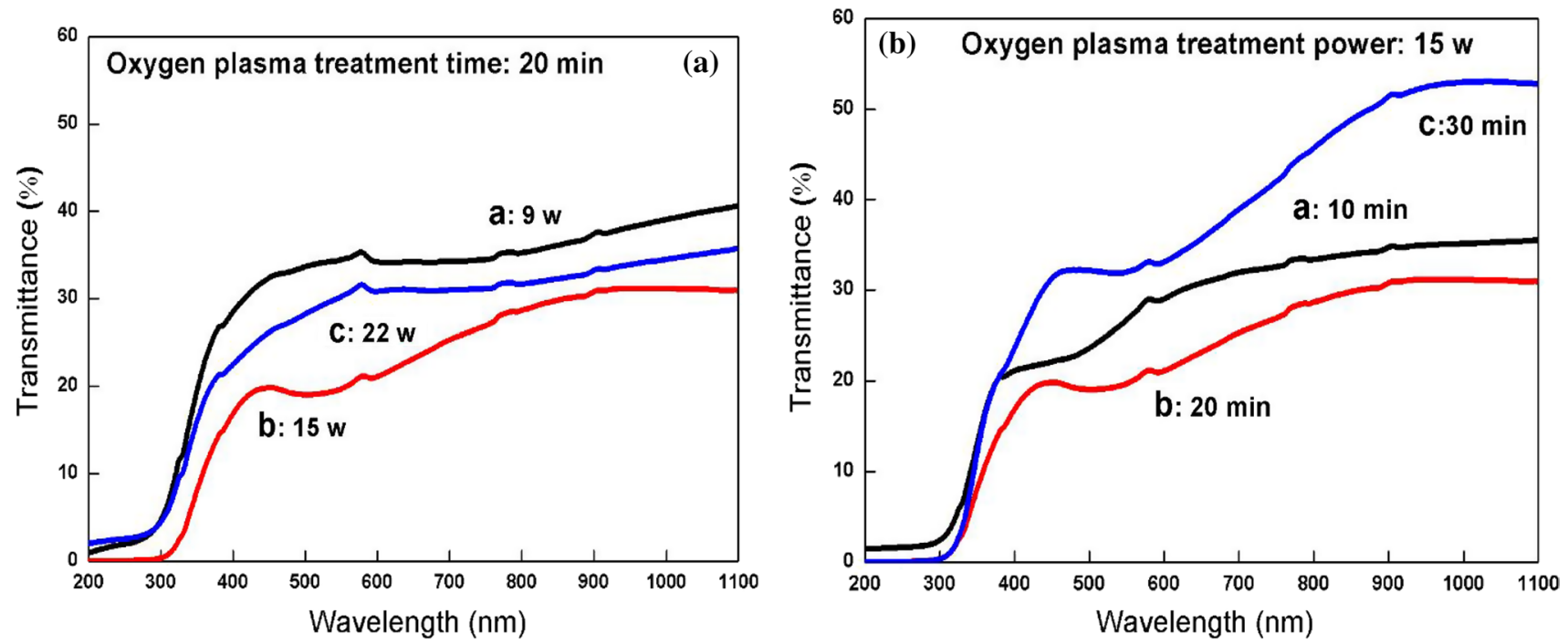

Fig. 10 Optical transmittance spectra of $\mathrm{NiO}$ films grown on quartz substrates at different: a plasma treatment powers and $\mathbf{b}$ treatment times 

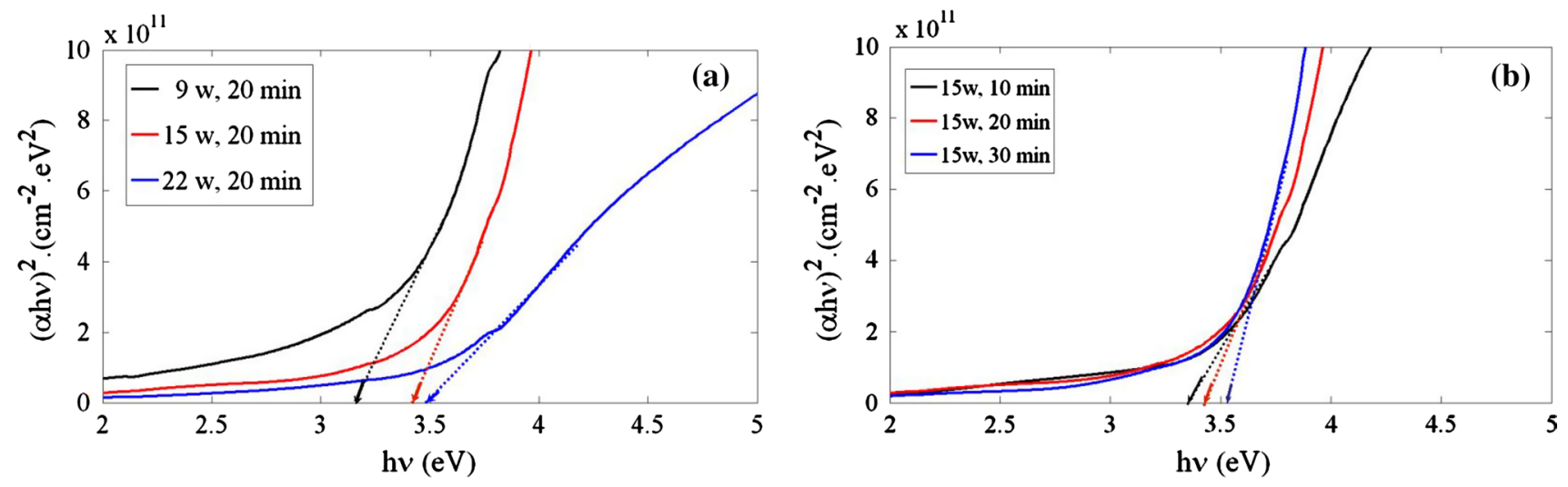

Fig. 11 The dependence of $(\alpha h \nu)^{2}$ on $(h \nu)$ for $\mathrm{NiO}$ thin films prepared at different plasma treatment: a powers and $\mathbf{b}$ times

transitions, respectively. In this work, the best linear fit for the $(\alpha h \nu)^{1 / p}$ versus $(h \nu)$ curve is obtained for $p=1 / 2$ indicating a direct allowed transition in the films. The variation of $(\alpha h \nu)^{2}$ as a function of the photon energy $(h \nu)$ for $\mathrm{NiO}$ thin films prepared at different plasma powers and times are depicted in Fig. 11a, b, respectively. The plots indicate a direct optical band gap for the investigated $\mathrm{NiO}$ films. The optical band gap energy is evaluated by extrapolating the linear part of the curve $(\alpha h \nu)^{2}$ where $(\alpha=0)$. It is found that from the figures, the deduced band gap energy of $\mathrm{NiO}$ films are in range of 3.20-3.51 eV. The band gap value of the $\mathrm{NiO}$ films obtained in the present work closely matches with the value reported by many authors $[8,11,14,20-23]$.

\section{Conclusion}

$\mathrm{NiO}$ thin films were prepared on quartz substrates using the plasma oxidation of $\mathrm{Ni}$ thin films. The effects of the plasma oxidation power and times on the structural, morphological and optical properties of nickel oxide thin films were reported in this paper. Plasma oxidation of nickel films caused the formation of densely packed nanocrystalline nickel oxide. According to AFM results, by increasing of plasma treatment powers, the surface roughness of films increased while the augmentation of plasma treatment time leads to decreasing the surface roughness of $\mathrm{NiO}$ films. The uniform nanosphere grains and crack-free high compact surfaces observed by FESEM implies a good crystallinity of films and consistent with the results obtained by XRD and AFM. Furthermore, the calculated optical band gap energy was in range $3.20-3.51 \mathrm{eV}$. The obtained results suggest that the nanocrystalline $\mathrm{NiO}$ thin films prepared by the plasma oxidation process have good optical properties. These $\mathrm{NiO}$ films are expected to be used in optoelectronic devices.
Open Access This article is distributed under the terms of the Creative Commons Attribution 4.0 International License (http://creativeco mmons.org/licenses/by/4.0/), which permits unrestricted use, distribution, and reproduction in any medium, provided you give appropriate credit to the original author(s) and the source, provide a link to the Creative Commons license, and indicate if changes were made.

\section{References}

1. Sta, I., Jlassi, M., Kandyla, M., Hajji, M., Koralli, P., Allagui, R., Kompitsas, M., Ezzaouia, H.: J. Alloys Compd. 626, 87-92 (2015)

2. Turgut, E., Coban, O., Sarıtas, S., Tuzemen, S., Yildirim, M., Gur, E.: Appl. Surf. Sci. 435, 880-885 (2018)

3. Soleimanpour, A.M., Jayatissa, A.H.: J. Mater. Sci. Eng. C 32 , 2230-2234 (2012)

4. Nalage, S.R., Chougule, M.A., Sen, S., Patil, V.B.: J. Mater. Sci. Mater. Electron. 24, 368-375 (2013)

5. Salazar, P., Garcia, F.J.G., Elipe, A.R.G.: Electrochem. Commun. 94, 5-8 (2018)

6. Wang, Y., Ghanbaja, J., Boulet, P., Horwat, D., Pierson, J.F.: Acta Mater. 164, 648-653 (2019)

7. Rashvand, S., Hojabri, A.: J. Inorg. Organomet. Polym. 27, 503509 (2017)

8. Mallikarjuna Reddy, A., Sivasankar Reddy, A., Lee, K., Sreedhara Reddy, P.: Ceram. Int. 37, 2837-2843 (2011)

9. Cao, L., Wang, D., Wang, R.: Mater. Lett. 132, 357-360 (2014)

10. Singh, A., Bhansali, S., Barton, D., Urban III, F.K.: Thin Solid Films 644, 23-28 (2017)

11. Ai, L., Fang, G., Yuan, L., Liu, N., Wang, M., Li, C., Zhang, Q., Li, J., Zhao, X.: Appl. Surf. Sci. 254, 2401-2405 (2008)

12. Huang, Q., Zhang, Q., Xiao, Y., He, Y., Diao, X.: J. Alloys Compd. 747, 416-422 (2018)

13. Ahmed, A.A., Devarajan, M., Afzal, N.: Mater. Sci. Semicond. Process. 63, 137-141 (2017)

14. Karpinski, A., Ferrec, A., Plouet, M.R., Cattin, L., Djouadi, M.A., Brohan, L., Jouan, P.Y.: Thin Solid Films 520, 3609-3613 (2012)

15. Peng, T.C., Xiao, X.H., Han, X.Y., Zhou, X.D., Wu, W., Ren, F., Jiang, C.Z.: Appl. Surf. Sci. 257, 5908-5912 (2011)

16. Zhang, Y.: Appl. Surf. Sci. 344, 33-37 (2015)

17. Seo, Y.K., Lee, D.J., Koh, Y.D., Chung, J.S., Lee, Y.S., Jo, Y.: J. Phys. D Appl. Phys. 42, 15407 (2009)

18. Hajakbari, F., Afzali, M.T., Hojabri, A.: Acta Phys. Pol. A 131(3), 417-419 (2017) 
19. Roffi, T.M., Nozaki, S., Uchida, K.: J. Cryst. Growt. 451, 57-64 (2016)

20. Gomaa, M.M., Boshta, M., Farag, B.S., Osma, M.B.S.: J. Mater. Sci. Mater. Electron. 27, 711-717 (2016)

21. Boukhachem, A., Boughalmi, R., Karyaoui, M., Mhamdi, A., Chtourou, R., Boubaker, K., Amlouk, M.: Mater. Sci. Semicond. Process. B188, 72-77 (2014)

22. Raut, B.T., Pawar, S.G., Chougule, M.A., Sen, S., Patil, V.B.: J. Alloys Compd. 509, 9065-9070 (2011)

23. Turgut, G., Sonmez, E., Duman, S.: Ceram. Int. 41, 2976-2989 (2015)

24. Ghamdi, A.A.A., Wahab, M.S.A., Farghali, A.A., Hasan, P.M.Z.: Mater. Res. Bull. 75, 71-77 (2016)

25. Sari, A.H., Ghorbani, S., Dorranian, D., Azadfar, P., Hojabri, A.R., Ghoranneviss, M.: Appl. Sur. Sci. 255, 2180-2218 (2008)

26. Van Viet, P., Phuong Trang, D.D., Dai Phat, B., Van Hieu, L., Thi, CMinh: Superlattices Microst. 117, 305-316 (2018)
27. Moradi, M., Solati, E., Darvishi, S., Dorranian, D.: J. Clust. Sci. 27(1), 127-138 (2016)

28. Jalili, S., Hajakbari, F., Hojabri, A.: J. Theor. Appl. Phys. 12, 15-22 (2018)

29. Dorranian, D., Dejam, L., Sari, A.H., Hojabri, A.: J. Theor. Appl. Phys. 3, 37-41 (2009)

30. Hajakbari, F., Ensandoust, M.: Acta Phys. Pol. A 129(4), 680-682 (2016)

31. Hojabri, A., Haghighian, N., Yasserian, K., Ghoranneviss, M.: IOP Conf. Ser. Mater. Sci. Eng. 12, 012004-012007 (2010)

Publisher's Note Springer Nature remains neutral with regard to jurisdictional claims in published maps and institutional affiliations. 